\title{
Induced ankylosis of a primary molar for skeletal anchorage in the mandible as alternative to mini-implants
}

\author{
Matina V Angelopoulou ${ }^{1 *}$, Despina Koletsi ${ }^{2}$, George Vadiakas ${ }^{3}$ and Demetrios J Halazonetis ${ }^{2}$
}

\begin{abstract}
Background: Mesial protraction of mandibular posterior teeth requires increased anchorage to avoid undesired tooth movements. Orthodontic mini-implants have become a popular and successful way to increase skeletal anchorage in such cases. However, mini-implants may cause injury to adjacent teeth or anatomical structures and may lead to tissue inflammation. Induced ankylosed primary teeth have been used in the past as abutments for the protraction of the maxilla in cases of maxillary retrognathism. However, this technique has not been described in the literature for the protraction of mandibular molars. The aim of this paper is to present, through a case report, an alternative to mini-implant devices to maximize anchorage in the mandible by inducing ankylosis on a primary molar.

Findings: A 13-year-old female with class II right malocclusion, deep bite, and congenitally missing right second premolars was referred for orthodontic treatment. Treatment plan involved removal of the primary teeth and mesial protraction of the posterior. In the mandible, ankylosis was induced on the retained primary second molar by extraction, bisection, replantation of the mesial part after endodontic treatment, and bonding of a rigid splint. Ankylosis was diagnosed after 10 weeks and a closing T-loop sectional wire was inserted to move the permanent first molar mesially. At 6 months, the remaining space was closed using elastic chain on a rectangular stainless steel wire with tip-back bends, supported by class II elastics.
\end{abstract}

Conclusions: Induced ankylosis of primary teeth can be an alternative to orthodontic mini-implants in selected cases, with minimal risks and maximum biocompatibility.

Keywords: Induced ankylosis; Molar protraction; Anchorage; Congenitally missing premolars

\section{Findings}

\section{Clinical examination}

A 13-year-old Caucasian female was referred for orthodontic treatment. The patient's medical history was noncontributory. Extraoral clinical examination revealed a symmetric face, normal proportions of the upper and lower facial height, a slightly convex profile, and an acute nasolabial angle. Intraoral clinical examination showed mild generalized gingivitis with fair oral hygiene and no caries. Evaluation of the occlusion revealed a dental class II molar and canine relationship on the right side and class I molar and canine relationship on the left

\footnotetext{
* Correspondence: matinangelop@yahoo.gr

'Division of Pediatric Dentistry, School of Dentistry, Marquette University, 1801 W Wisconsin Ave, 53233 Milwaukee, WI, USA

Full list of author information is available at the end of the article
}

side, deep bite, slight malalignment of the anterior teeth, and deviation of the mandibular midline to the right by $2 \mathrm{~mm}$. Both maxillary and mandibular right second primary molars were present while all other primary teeth had exfoliated (Fig. 1).

Radiographic examination revealed congenitally missing right second premolars and all third molars (Fig. 2a). Cephalometric analysis showed a skeletal class I relationship and hyperdivergent skeletal pattern (Fig. 2b, Table 1).

\section{Treatment alternatives}

Correction of the canine relationship, overbite, and midline discrepancy would be accomplished using fixed appliances. Regarding the agenesis of the second premolars, the patient was offered two choices: maintain the primary molars and prosthetically replace them when they would 

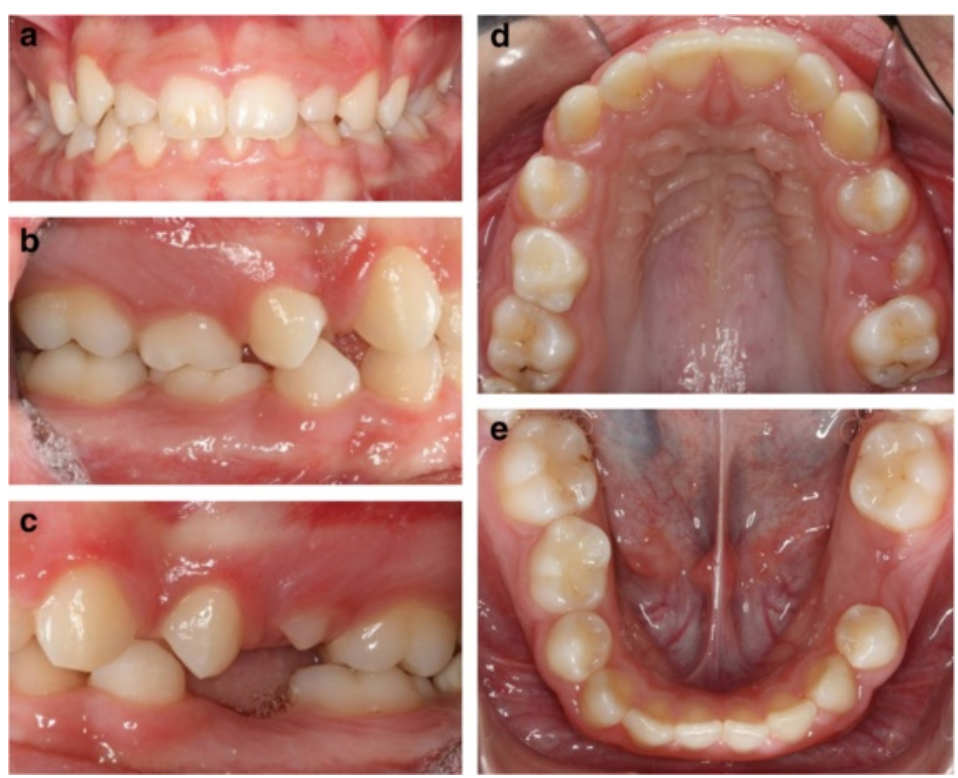

Fig. 1 Initial clinical examination of a frontal view, b right lateral view, c left lateral view, d maxillary occlusal view, and e mandibular occlusal view
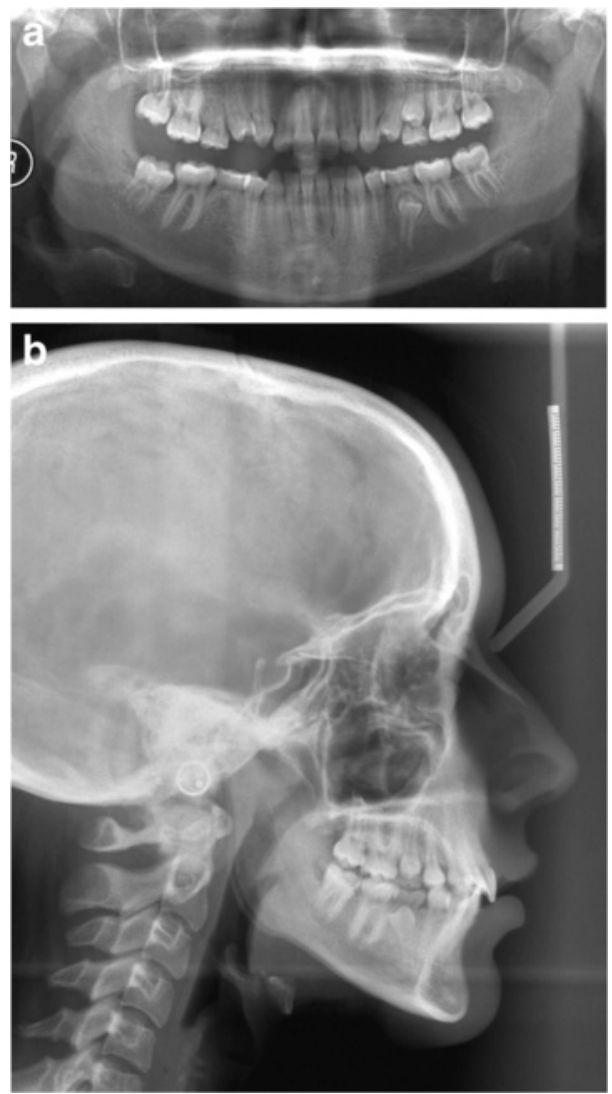

Fig. 2 a Panoramic radiograph showing congenitally missing right 2nd premolars. $\mathbf{b}$ Cephalometric radiograph at the start of treatment eventually exfoliate, or extract them and close the space by mesial movement of the first and second permanent molars $[1,2]$. The patient decided to follow the second option in order to avoid the need for implants or other prostheses in the future.

Mesial movement of molars is taxing on anchorage, especially in the mandibular arch [3-5]. Considering that the mandibular midline was already shifted to the agenesis side, skeletal anchorage was deemed an efficient option. However, instead of placing a mini-implant $[3,5,6]$, we decided to use the primary molar as a biological alternative. We induced ankylosis and used the mesial root as skeletal anchorage. Induced ankylosed primary teeth have been used in the past as abutments for the

Table 1 Initial and final cephalometric measurements

\begin{tabular}{lrr}
\hline & Initial & Final \\
\hline SNA $\left(^{\circ}\right)$ & 76.4 & 76.8 \\
SNB $\left(^{\circ}\right)$ & 73.3 & 72.7 \\
ANB $\left(^{\circ}\right)$ & 3.1 & 4.1 \\
Wits $(\mathrm{mm})$ & 0.2 & -0.4 \\
SN to GoGn $\left(^{\circ}\right)$ & 42.8 & 42.9 \\
Maxillary incisor to NA $\left(^{\circ}\right)$ & 19.8 & 13.4 \\
Maxillary incisor to NA $(\mathrm{mm})$ & 4.1 & -0.1 \\
Mandibular incisor to NB $\left(^{\circ}\right)$ & 25.5 & 27.6 \\
Mandibular incisor to NB $(\mathrm{mm})$ & 4.4 & 3.9 \\
Interincisal angle $\left(^{\circ}\right)$ & 131.6 & 134.9 \\
Mandibular incisor to $\mathrm{GoGn}\left({ }^{\circ}\right)$ & 89.5 & 92.0 \\
\hline
\end{tabular}


protraction of the maxilla in cases of maxillary retrognathism [7-9]. However, this technique has not been described in the literature for the protraction of mandibular molars.

\section{Treatment steps}

The ankylosis technique included extraction of the primary molar under local anesthesia followed by root canal treatment of the mesial root, performed ex vivo using a zinc oxide and eugenol sealer (Fig. 3a). The crown was then restored with composite resin and a 2-mm apicoectomy and hemisectomy of the tooth was performed (Fig. 3b). To induce ankylosis, we followed the management protocol for avulsed teeth with a closed apex and extraoral dry time exceeding $60 \mathrm{~min}$ [10]. Periodontal ligament cells were removed from the root surface with a scaler. Sixty minutes after the extraction of the tooth, the socket was irrigated with saline solution and the mesial root was replanted with slight pressure. To stabilize the tooth and assure ankylosis, a rigid splint was applied, extending from the right canine to the right first molar, using a $0.016^{\prime \prime} \times 0.022$ " stainless steel (SS) rectangular wire (Fig. 3c).

Ankylosis of the mesial root of the primary mandibular right second molar was diagnosed after 10 weeks through clinical and radiographic examination, and the splint was removed (Fig. 4). Next, a band was placed on the permanent mandibular right first molar and brackets were bonded on the primary second molar and the mandibular first premolar. A closing T-loop $0.017 " \times 0.025$ " TMA sectional wire was inserted between the permanent and primary molar, without any prior levelling, to move the permanent first molar mesially (Fig. 5). The T-loop was activated 9 times. At 6 months, clinical and radiographic examination revealed almost total replacement resorption of the root of the primary tooth and complete closure of the space (Fig. 6). Consequently, the bisected primary tooth was extracted and full orthodontic treatment followed. Remaining space closure was performed, during the next year, using elastic chain on a $0.017^{\prime \prime} \times$ 0.025 " SS wire with tip-back (Fig. 7) and support from class II elastics.

Final records show class I canine and molar relationship on both sides; full space closure of the agenesis sites, confirmed with the use of dental floss; and correction of overbite and overjet; however, a slight midline deviation remained (Figs. 8 and 9a). Cephalometric analysis showed that the mandibular incisors did not experience lingual movement as a result of molar protraction (Fig. 9b, Table 1).
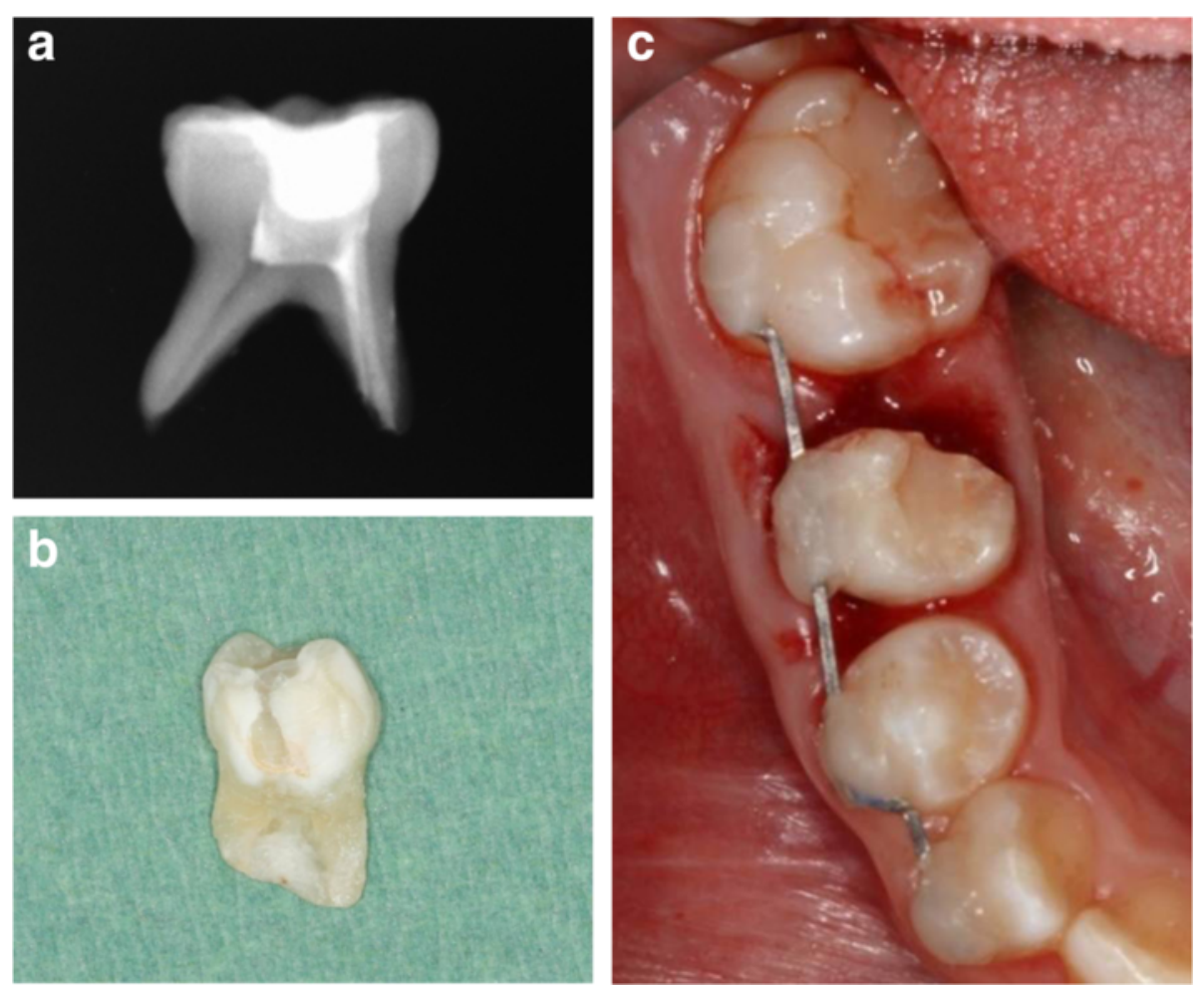

Fig. 3 Induced ankylosis technique $\mathbf{a}$ extraoral root canal treatment of the mesial root of the primary tooth, $\mathbf{b}$ hemisectomy of the primary tooth, and $\mathbf{c}$ replantation of the mesial part and splinting 


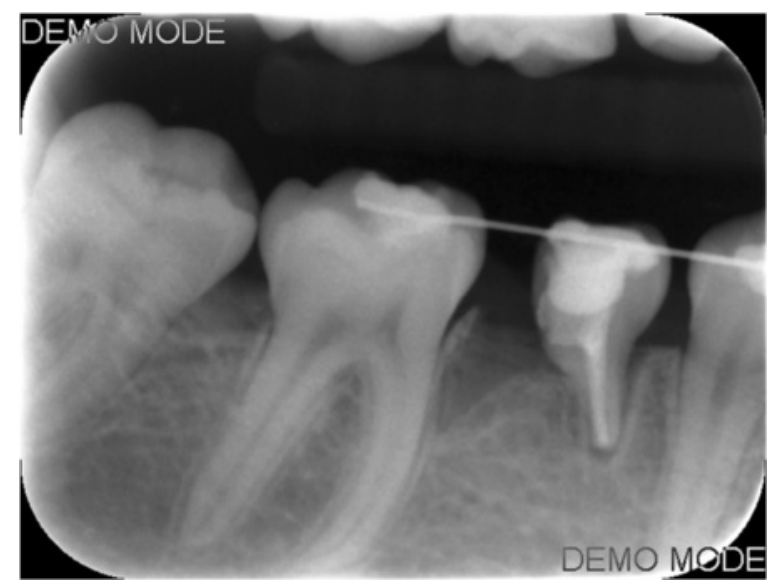

Fig. 4 Radiograph 10 weeks post replantation showing the absence of periodontal ligament and root ankylosis

\section{Discussion}

Induced ankylosed primary teeth can be used in place of temporary anchorage devices to maximize anchorage during orthodontic treatment. The technique used in the present case was based on the treatment protocol for avulsed teeth exceeding $60 \mathrm{~min}$ extraoral dry time, as suggested by the International Association of Dental Traumatology [11]. However, the tooth was not placed in $2 \%$ sodium fluoride for 20 min since the goal of this step is to postpone osseous replacement of the root [10], which was not a desired outcome in this case. Also, a rigid splint was used to further assure tooth ankylosis [12]. Previous studies that have reported induced ankylosis for orthodontic protraction have used similar techniques [7-9].

Several treatment alternatives have been proposed for the management of congenital missing premolars. In cases of deep bite, spacing, and class I occlusion, the primary tooth can be kept in place until it exfoliates $[2,13]$. In cases of congenitally missing premolars, the primary predecessors usually exfoliate when the patient is an

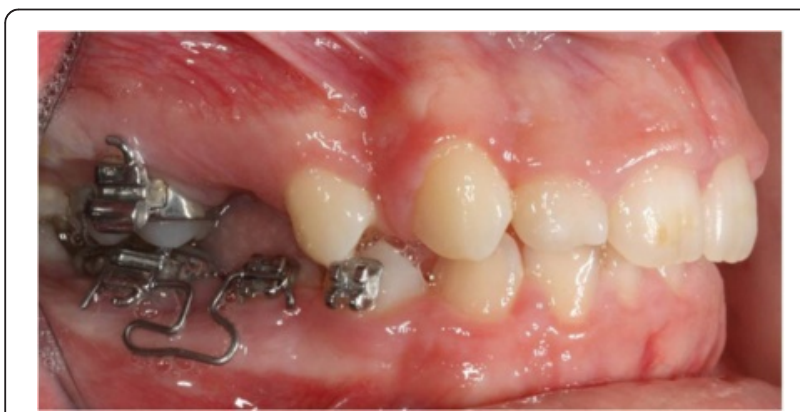

Fig. 5 Initial orthodontic space closure using a T-loop to close the space between the primary molar segment and the permanent first molar

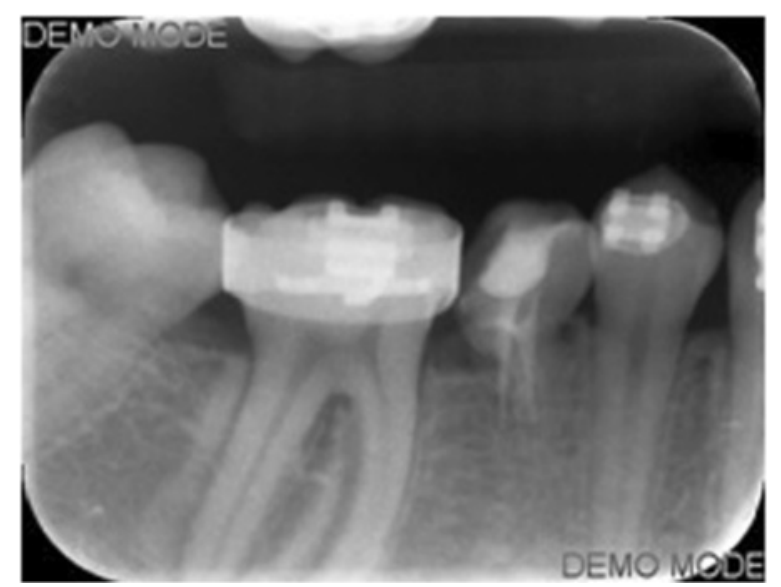

Fig. 6 Radiograph 6 months post replantation showing almost total root resorption and complete space closure between the 1st permanent molar and 2nd primary molar

adult $[13,14]$ and an implant can be placed, as the alveolar bone has usually been preserved $[2,15]$. However, it is difficult to restore the implant since the mesiodistal dimension of the primary tooth is greater than the missing premolar and additional orthodontic treatment may be required $[2,14,16]$.

An option to avoid future restorative compromise, especially when orthodontic treatment is inevitably required, is to modify the primary molar [2] by trimming it mesially and distally and restoring it as a premolar [2]. Orthodontic treatment follows and, when the primary molar exfoliates, it is replaced by an implant [2].

When the primary molar has extensive caries, restorations, or resorption, extraction is an option [1, 14]. The space can then be preserved with a space maintainer or an implant placed if the patient is an adult $[2,3,15]$. In all implant cases mentioned above, a fixed prosthesis is also an alternative [3]. It is crucial to note that when

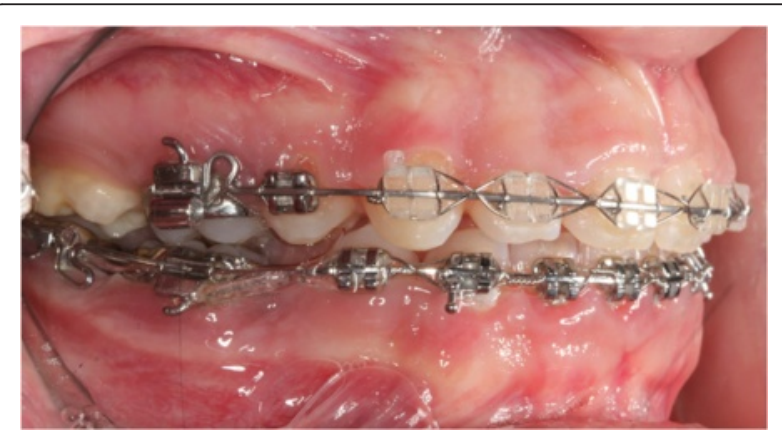

Fig. 7 Orthodontic space closure using a retraction elastic chain to close the space between the permanent first molar and the first premolar; a stop was added to the wire to maximize anchorage 

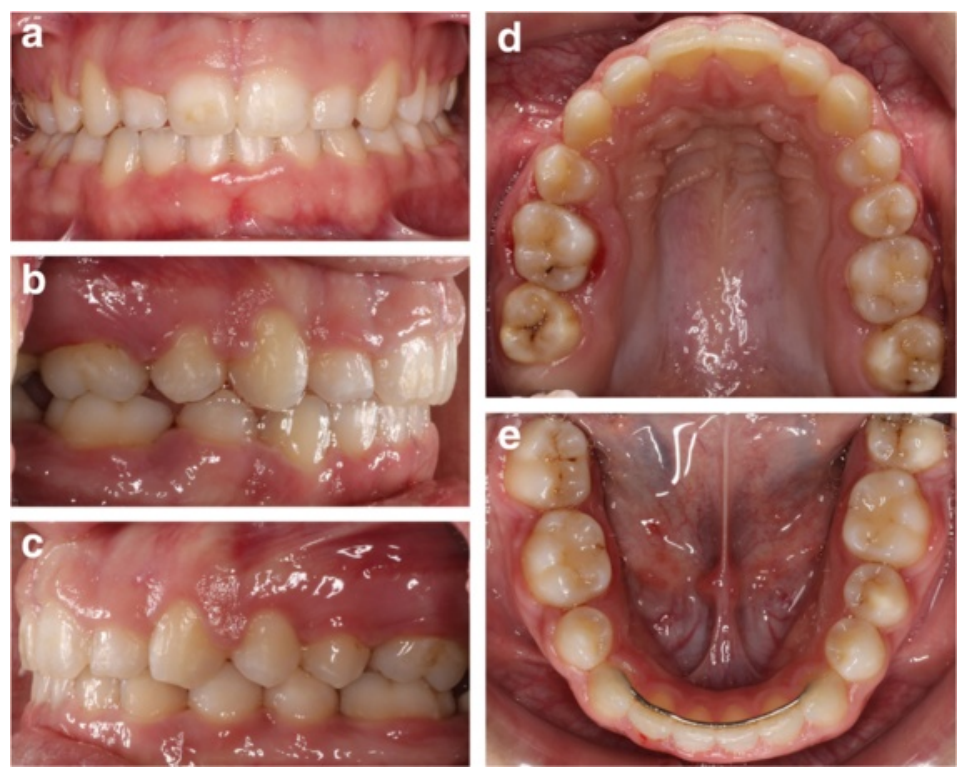

Fig. 8 Clinical examination after the completion of orthodontic treatment showing the 1st permanent molar in the position of the 2nd premolar a frontal view, $\mathbf{b}$ right lateral view, $\mathbf{c}$ left lateral view, $\mathbf{d}$ maxillary occlusal view, and e mandibular occlusal view
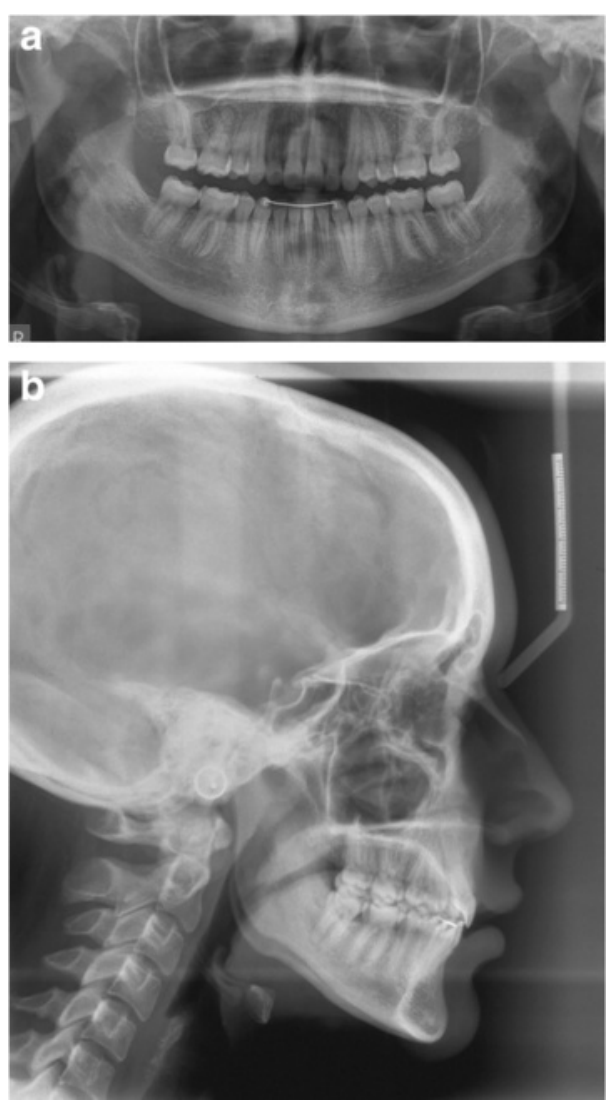

Fig. 9 a Panoramic radiograph at the end of orthodontic treatment showing the 1st permanent molar in the position of the 2nd premolar. b Final cephalometric radiograph space is maintained for a long time, alveolar bone can become atrophic and implant placement is challenging $[2,4]$. Finally, autotrasplantation of premolars or molars may also be an alternative [17].

In cases of crowding, class II malocclusion, severely damaged primary molars, or when the patient rejects the option of a prosthesis, space closure is the treatment of choice $[1,2]$. When the patient is under the age of 8 years, spontaneous space closure can be achieved $[18,19]$. The key point is to detect the premolar agenesis prior to root completion of the first permanent molar $[18,19]$. However, even then, mild tipping of adjacent teeth can be observed $[18,19]$.

An alternative to space closure is the use of conventional orthodontics. In our case, this was the choice of treatment for the space closure in the maxilla, where cortical alveolar bone is less compact and thus orthodontic bodily movement is easier [20]. However, in the mandible, due to the bone's compact architecture, bodily movement is compromised leading to loss of anchorage and undesired tooth movement $[3,5,2021]$. Lingual functional appliances [22], intermaxillary elastics [4, 16], and mandibular protraction appliances [21] have been proposed for space closure in the mandible to avoid molar tipping and anchorage loss.

Another option is controlled slicing and hemisectomy $[14,23]$. Controlled slicing starts with progressive trimming of the distal surface of the primary molar which leads to hemisectomy of the tooth [14]. The hemisectomy technique is similar to the one used for induced ankylosis; 
however, the primary molar is not ankylosed and cannot be used as an immovable abutment. Hemisectomy diminishes the risk of bone atrophy in the extraction site and of extreme mesial inclination of the first permanent molar $[14,23]$. However, undesired movement of the anterior teeth cannot be totally prevented [23].

Recently, orthodontic mini-implants have been used successfully for space closure in mandibular molar protraction $[2,3,6,24]$. However, they have the risk of soft tissue inflammation, damage of anatomical structures during implant placement, lack of stability, and implant fracture [25-27]. On the contrary, an induced ankylosed tooth has maximum biocompatibility leading to low inflammation risks when appropriate oral hygiene is performed. Furthermore, there is no risk to damage anatomical structures during replantation since the tooth is put in the existing socket. Finally, the root of the ankylosed tooth at the time of final extraction has almost totally been replaced by bone diminishing the risk of fracture.

The proposed technique is conservative and has advantages since (a) half of the tooth is retained, thereby retaining the alveolar process during the first phase of protraction, and (b) even if ankylosis fails to develop, other options are still open, because the tooth can be extracted and treatment can continue using other methods (e.g., mini-implant). However, this technique is indicated only for cooperative patients since procedures are timeconsuming and treatment requires several visits. In addition, treatment cost can be high compared to miniimplants. Also, the ankylosed abutment cannot be placed wherever is required but where the primary tooth is located and is only partially exploited since the ankylosed root has to be extracted after $4-5 \mathrm{~mm}$ of protraction.

\section{Abbreviations}

TMA: Titanium molybdenum alloy; SS: Stainless steel.

\section{Competing interests}

The authors declare that they have no competing interests.

\begin{abstract}
Authors' contribution
MVA performed the treatment on the primary molar to induce its ankylosis and drafted the initial manuscript. DK carried out the orthodontic treatment. GV supervised the treatment and edited the manuscript. DJH designed the treatment plan for the patient, supervised the treatment and the follow-up of the patient, and edited the manuscript. All authors read and approved the final manuscript.
\end{abstract}

\section{Acknowledgements}

The authors would like to thank Dr. Yiannis Lyros and Dr. Alina Cocos for the follow-up of the patient's orthodontic treatment. Informed consent for publication of the presented case was obtained by the parent and the child.

\section{Author details}

'Division of Pediatric Dentistry, School of Dentistry, Marquette University, 1801 W Wisconsin Ave, 53233 Milwaukee, WI, USA. ²Department of Orthodontics, School of Dentistry, National and Kapodistrian University of Athens, 2 Thivon Str., 11527 Athens, Greece. ${ }^{3}$ Department of Paediatric Dentistry, School of Dentistry, National and Kapodistrian University of Athens, 2 Thivon Str., 11527 Athens, Greece.
Received: 27 January 2015 Accepted: 9 June 2015

Published online: 18 June 2015

\section{References}

1. Santos $L L$. Treatment planning in the presence of congenitally absent second premolars: a review of the literature. J Clin Pediatr Dent. 2002;27(1):13-7.

2. Kokich VG, Kokich VO. Congenitally missing mandibular second premolars: clinical options. Am J Orthod Dentofacial Orthop. 2006;130(4):437-44. doi:10.1016/j.ajodo.2006.05.025.

3. Nagaraj K, Upadhyay M, Yadav S. Titanium screw anchorage for protraction of mandibular second molars into first molar extraction sites. Am J Orthod Dentofacial Orthop. 2008;134(4):583-91. doi:10.1016/j.ajodo.2006.09.055.

4. Saga AY, Maruo IT, Maruo H, Guariza Filho O, Camargo ES, Tanaka OM. Treatment of an adult with several missing teeth and atrophic old mandibular first molar extraction sites. Am J Orthod Dentofacial Orthop. 2011;140(6):869-78. doi:10.1016/j.ajodo.2010.06.027.

5. Baik UB, Chun YS, Jung MH, Sugawara J. Protraction of mandibular second and third molars into missing first molar spaces for a patient with an anterior open bite and anterior spacing. Am J Orthod Dentofacial Orthop. 2012;141(6):783-95. doi:10.1016/j.ajodo.2010.07.031.

6. Mimura H. Protraction of mandibular second and third molars assisted by partial corticision and miniscrew anchorage. Am J Orthod Dentofacial Orthop. 2013;144(2):278-89. doi:10.1016/j.ajodo.2012.08.030.

7. Kokich VG, Shapiro PA, Oswald R, Koskinen-Moffett L, Clarren SK. Ankylosed teeth as abutments for maxillary protraction: a case report. Am J Orthod. 1985;88(4):303-7.

8. Omnell ML, Sheller B. Maxillary protraction to intentionally ankylosed deciduous canines in a patient with cleft palate. Am J Orthod Dentofacial Orthop. 1994;106(2):201-5.

9. Da Silva Filho OG, Ozawa TO, Okada CH, Okada HY, Carvalho RM. Intentional ankylosis of deciduous canines to reinforce maxillary protraction. J Clin Orthod. 2003;37(6):315-20. quiz 3 .

10. Andreasen FMAJ. Avulsions. In: Andreasen JOAF, Andersson L, editors. Textbook and color atlas of traumatic injuries to the teeth. 4th ed. Oxford: Blackwell; 2007. p. 444-88.

11. Andersson L, Andreasen JO, Day P, Heithersay G, Trope M, Diangelis AJ, et al. International Association of Dental Traumatology guidelines for the management of traumatic dental injuries: 2. Avulsion of permanent teeth. Dent Traumatol Off Publ Int Assoc Dent Traumatol. 2012;28(2):88-96. doi:10.1111/j.1600-9657.2012.01125.x.

12. Andreasen JO, Borum MK, Jacobsen $\mathrm{HL}$, Andreasen FM. Replantation of 400 avulsed permanent incisors. 4. Factors related to periodontal ligament healing. Endod Dent Traumatol. 1995;11(2):76-89.

13. Bjerklin $\mathrm{K}$, Bennett J. The long-term survival of lower second primary molars in subjects with agenesis of the premolars. Eur J Orthod. 2000;22(3):245-55.

14. Valencia R, Saadia M, Grinberg G. Controlled slicing in the management of congenitally missing second premolars. Am J Orthod Dentofacial Orthop. 2004;125(5):537-43. doi:10.1016/50889540603010874.

15. Sabri R. Management of congenitally missing second premolars with orthodontics and single-tooth implants. Am J Orthod Dentofacial Orthop. 2004;125(5):634-42. doi:10.1016/\$0889540604000022.

16. Fines CD, Rebellato J, Saiar M. Congenitally missing mandibular second premolar: treatment outcome with orthodontic space closure. Am J Orthod Dentofacial Orthop. 2003;123(6):676-82. doi:10.1016/50889540603001628.

17. Josefsson E, Brattstrom V, Tegsjo U, Valerius-Olsson H. Treatment of lower second premolar agenesis by autotransplantation: four-year evaluation of eighty patients. Acta Odontol Scand. 1999;57(2):111-5.

18. Lindqvist B. Extraction of the deciduous second molar in hypodontia. Eur J Orthod. 1980;2(3):173-81

19. Mamopoulou A, Hagg U, Schroder U, Hansen K. Agenesis of mandibular second premolars. Spontaneous space closure after extraction therapy: a 4-year follow-up. Eur J Orthod. 1996;18(6):589-600.

20. Roberts WE. Bone physiology, metabolism and biomechanics in orthodontic practice. In: Graber TM, Vanarsdall RL, editors. Orthodontics: current principles and techniques. St. Louis: Mosby; 1994. p. 193-257.

21. Coelho CM, Coelho F, White LW. Treatment of a mutilated dentition with the mandibular protraction appliance: a patient report. World J Orthod. 2009;10(4):378-82.

22. Kocadereli I, Cijger S. Congenitally missing teeth: an alternative approach for space closure. J Clin Pediatr Dent. 1993;17(4):213-6. 
23. Northway W. Hemisection: one large step toward management of congenitally missing lower second premolars. Angle Orthod. 2004;74(6):792-9. doi:10.1043/0003-3219(2004)074<0792:HOLSTM>2.0.CO;2.

24. Giuliano Maino B, Pagin P, Di Blasio A. Success of miniscrews used as anchorage for orthodontic treatment: analysis of different factors. Prog Orthod. 2012;13(3):202-9. doi:10.1016/j.pio.2012.04.002.

25. Papadopoulos MA, Tarawneh F. The use of miniscrew implants for temporary skeletal anchorage in orthodontics: a comprehensive review. Oral Surg Oral Med Oral Pathol Oral Radiol Endod. 2007;103(5):e6-15. doi:10.1016/j.tripleo.2006.11.022.

26. Tsui WK, Chua HD, Cheung LK. Bone anchor systems for orthodontic application: a systematic review. Int J Oral Maxillofac Surg. 2012;41(11):1427-38. doi:10.1016/j.jom.2012.05.011.

27. Luzi C, Verna C, Melsen B. A prospective clinical investigation of the failure rate of immediately loaded mini-implants used for orthodontic anchorage. Prog Orthod. 2007;8(1):192-201.

Submit your manuscript to a SpringerOpen ${ }^{\circ}$ journal and benefit from:

- Convenient online submission

- Rigorous peer review

- Immediate publication on acceptance

- Open access: articles freely available online

- High visibility within the field

- Retaining the copyright to your article

Submit your next manuscript at $>$ springeropen.com 